\title{
Sorria: você está sendo filmado. A espetacularização da prática policial e o trabalho de limpeza moral
}

\author{
Amanda Dinucci Almeida Buhler Velasco ${ }^{a}$ \\ Maria do Carmo Leite Oliveira ${ }^{b}$
}

\begin{abstract}
Resumo
A espetacularização da vida cotidiana tornou-se mais democrática com o acesso às tecnologias de imagem oferecidas pelo telefone celular. Nessa esteira, estão os vídeos produzidos por cidadãos que registram a ação policial em comunidades em processo de pacificação. À luz de uma abordagem da Análise da Conversa Aplicada (ANTAKI, 2011) e dos estudos sobre multimodalidade (GOODWIN, 2010), analisamos, para este trabalho, um vídeo, postado na internet, que registra a cena de condução de um suspeito à delegacia, logo após uma ação de abordagem. Considerando-se que os policiais estão cientes da gravação e conscientes de que a imagem de policial está sob constante suspeição (MUNIZ, 1998), pretende-se investigar como os policiais vão gerenciar a interação física e virtual para realizar um trabalho de limpeza moral (MACHADO DA SILVA, 2008) que possa reparar seu estigma. Como mostra a análise realizada, a mediação tecnológica favorece a disputa dos policiais pela direção/edição do espetáculo, através de mecanismos como inclusão de informações não captadas pelo cinegrafista e explicitação das normas que orientam suas ações, especialmente no que diz respeito ao uso da força. Através de um trabalho de limpeza moral, os policiais buscam (re) construir a imagem de profissionais que agem de acordo com os preceitos da ética policial-militar, como o exercício de suas funções com probidade e justiça.
\end{abstract}

Palavras-chave: espetacularização; prática policial; Unidades de Polícia Pacificadora; limpeza moral; mediação tecnológica.

\footnotetext{
a Doutoranda em Estudos de Linguagem na PUC-Rio, amandadinucci@hotmail.com

b Professora Adjunta da PUC-Rio, mcleitedeoliveira@gmail.com
} 


\section{Introdução}

O quanto a noção de espetáculo ainda pode nos ajudar a compreender o mundo contemporâneo? A pergunta, colocada por Portela Júnior (2009), em sua resenha do livro A Sociedade do Espetáculo, de Guy Debord (1967) nunca foi tão pertinente como nos dias de hoje, em que a produção de espetáculos tornou-se mais democrática. $\mathrm{O}$ acesso do cidadão comum às tecnologias de imagem oferecidas pelos telefones celulares e a facilidade de compartilhamento de imagens no mundo paralelo da web expandiram o campo de produção do espetáculo, restrito, nos estudos de Debord (1967), ao universo dos meios de comunicação de massa tradicionais.

Tornou-se prática corriqueira a espetacularização de eventos cotidianos e sua postagem no território livre das redes sociais. Grande parte da difusão de material visual produzido por cidadãos comuns circula em redes, como o Youtube, com um número de visualizações que pode chegar, em alguns casos, a superar o público de um blockbuster. Com um alcance mais modesto, mas de difusão massiva, estão os vídeos que registram a atuação de policiais militares em comunidades cariocas em processo de pacificação. Gravados por quem assiste e/ou participa da cena registrada, esses vídeos têm-se mostrado um instrumento de empoderamento do cidadão comum e podem ser vistos como um fenômeno cultural típico de uma sociedade violenta e orientada para a vigilância (BRUNO, 2009).

Considerando-se que, em algumas dessas gravações, os vigiados - os policiais - estão cientes da gravação, o espetáculo da prática policial torna-se, como os talkshows (KATRIEL, 1999), um espaço de performances, deliberadas ou semideliberadas, especialmente, no caso em estudo, em que se sabe que a imagem do policial está sob constante suspeição (MUNIZ, 1998). O objetivo deste trabalho é investigar como os policiais vão gerenciar a interação física e a virtual para realizar um trabalho de limpeza moral (MACHADO DA SILVA, 2008) que possa reparar o estigma de desacreditados (GOFFMAN, 1978).

O foco do trabalho é uma análise multimodal de um vídeo postado no Youtube, que registra a condução de um suspeito à delegacia, após uma abordagem, numa comunidade em processo de pacificação. Este estudo se insere no âmbito de 
uma Linguística Aplicada das Profissões (SARANGI, 2006) que busca, com o apoio das contribuições da Análise da Conversa, iluminar problemas interacionais cujo entendimento, discutido colaborativamente com os profissionais envolvidos, pode ter um alcance intervencionista (ANTAKI, 2011), ou seja, o de uma solução para conflitos ou impasses que comprometem a eficácia de uma dada prática profissional.

\section{Artefatos tecnológicos e interação social}

Como coloca Hutchby (2001, p. 13), analisar as formas pelas quais as tecnologias para comunicação podem tornarse envolvidas com a interação requer uma discussão sobre as relações entre tecnologia e processos sociais (OLIVEIRA \& PEREIRA, 2005). Neste trabalho, assumimos a posição de Hutchby, que propõe como foco analítico o exame do que as pessoas fazem com as possibilidades e restrições para ação oferecidas pelos artefatos tecnológicos.

No caso do vídeo em estudo, a integração da tecnologia de imagem à tecnologia de transmissão de dados tem usos muito específicos por parte dos participantes, o que tem implicações no formato da interação.

Em termos de orientação, observa-se que os participantes, especialmente aquele que grava e os policiais, estão orientados ora para seus ouvintes ratificados, na interação situada (GOFFMAN, 1964), ora para o alvo da gravação, uma audiência oculta. Essa dupla orientação coloca, portanto, em superposição o campo interacional situado e o campo interacional projetado.

\section{Excerto 1}

Fala do cinegrafista (Vitor) projetada para uma audiência oculta:

09 ROBERTO: Algema [ele aí. Algema aí, algema aí... por desobediência.]

10 VITOR: [POLICIAL AGREDINDO MORATDOR NA HORA QUE CHE- QUE

11 ACABOU DE CHEGAR DO TRABALHO.]

\section{Excerto 2}

Fala do policial dirigindo o corpo e o olhar para a câmera:

12 RENAN: É o QUÊ? Vai me dar uma queda, ele falou que vai me dar uma queda hhh. 
Ouso do telefone celular, como tecnologia de comunicação, possibilitou também a entrada de um outro participante distante (aquele que liga para o cinegrafista), o que provocou um realinhamento de contextos (KATRIEL,1999):

\section{Excerto 3}

\begin{tabular}{lll}
\hline 71 & ROBERTO: & Pera aí, vai na moral. Pode ir na moral? \\
72 & VITOR: & Vocês acharam ele com alguma coisa? \\
73 & & $(($ um celular toca e Vitor atende)) \\
74 & VITOR: & Os caras estão com João aqui. Está dando a maior merda aqui. Espera aí. To \\
75 & & $\underline{\text { ocupadão. }}$ \\
76 & JOÃO: & Tu é um frouxo, cara. Vamos ver se tu é sujeito homem. Papo reto. Tu vai \\
77 & & tomá-lhe um quedão meu, parceiro. \\
78 & RENAN: & ((vira-se para Vitor sorrindo)) Filma aí... hhhh... Isso aí. Filma aí. Filma aí. \\
\hline
\end{tabular}

Como mostra a sequência, expande-se o campo interacional, com a justaposição de interações focalizadas e envolvimentos paralelos (GOFFMAN, 1967, p. 113), mas que entram em diálogo uma vez que o cinegrafista explica a sua impossibilidade de atender pela sua tarefa de guardião da segurança do suspeito, ao tentar controlar a ação dos policiais.

Em resumo, a tecnologia da imagem foi usada para a prática da vigilância; a tecnologia de transmissão de dados via internet habilitou o apagamento das fronteiras entre o contexto situacional local e privado e o contexto distanciado e público. Por sua vez, o telefone celular, que permite o acesso a qualquer pessoa em qualquer lugar, traz à cena real e virtual um tipo de intrometido, isto é, um participante distante sem uma função no espetáculo.

\section{Dos espetáculos da mídia tradicional aos espetáculos da internet}

O conceito de sociedade do espetáculo foi cunhado pelo pensador francês Guy Debord (1997, p. 13) para retratar um contexto em que "tudo o que era vivido diretamente tornouse representação". A espetacularização, produzida pelos meios de comunicação de massa, foi vista por ele como um mecanismo fundamental para a movimentação do consumo, ao criar pseudonecessidades (PORTELA JÚNIOR, 2009; PINTO, 
2005), o que tornaria o público refém do espetáculo e de quem o produzia. Como observou o autor, mais do que um mero conjunto de imagens, esses espetáculos desempenham um importante papel na constituição das relações sociais.

É fundamental, para compreendermos o trabalho de Debord, perceber que a manipulação que se realizaria por meio de espetáculos é apresentada pelo autor como "uma permanente Guerra do Ópio, que tem como objetivos embriagar a consciência dos atores sociais e fazer com que eles se identifiquem com as mercadorias que estão sendo oferecidas pela indústria cultural e que venham a consumi-las" (NEGRINI \& AUGUSTI, 2013, p. 7).

Entretanto, diferentemente dos espetáculos produzidos no universo da mídia, o que se observa no tipo de vídeo que é objeto deste trabalho é que o seu produtor usa a imagem como um instrumento de empoderamento de quem não tem voz. O potencial desses espetáculos para esse fim já resultou na criação de guias para gravação, como os produzidos pela ONG Witness, que explicam como produzir vídeos com segurança, para denunciar a truculência policial. Um ensina a registrar as ações policiais em manifestações. Outro ensina moradores de comunidades carentes a filmarem a ação da polícia quando acreditem sofrer uma violação dos seus direitos, dentre outras cartilhas que têm sido produzidas. Fica claro, portanto, que as facilidades da tecnologia de imagem oferecida pelo celular começam a ser tratadas como um produto - o vídeo-denúncia - cujo uso vai exigir um conhecimento perito dos seus produtores.

Do mesmo modo, as possibilidades oferecidas pelo celular para o compartilhamento do registro com uma audiência heterogênea e anônima podem levar, como, no caso em estudo, a uma disputa explícita sobre a verdade dos fatos, como se pode ver na sequência abaixo:

\section{Excerto 4}

85 LUÍS: $\quad$ Na hora que ele xinga os outros, você não filma.

86 VITOR: Ele NÃO TE XINGOU.<Só meteu a mão no bolso pra tirar os pertences dele>

87 [<Ele só meteu a mão no bolso pra tirar os pertences dele.>] < Ele só meteu a

88 mão no bolso pra tirar os pertences dele, MAIS NADA>.

89 LUís: [Na hora que ele xinga, os outros tu não filma.] 
Como se pode ver, o objetivo do cinegrafista é o de denunciar que a condução à delegacia foi uma prática injusta, fruto de um possível mal-entendido quanto ao gesto do suspeito de colocar a mão no bolso quando foi abordado. Já o objetivo do policial é o de mostrar, nas linhas 85 e 89, a orientação tendenciosa do cinegrafista na edição do vídeo, selecionando o que comunicar à plateia.

Diferentemente dos espetáculos de Debord, portanto, aquele que vai assistir ao vídeo não estará completamente de mãos atadas e com a consciência adormecida. A disputa entre os participantes na edição do vídeo pode dar ao público dúvidas quanto à interpretação correta dos fatos.

\section{Performance policial, estigma e limpeza moral}

De acordo com Prosise e Johnson (2004), o conhecimento que a maioria das pessoas tem do crime e sua compreensão do cumprimento da lei, em geral, deriva mais da mídia do que de experiências pessoais. No contexto estadunidense, por exemplo, uma pesquisa realizada por Eschholz et al (2002), sugere que assistir às notícias colabora para a formação de uma opinião favorável à polícia.

No caso do Brasil, pode-se supor que a formação de uma opinião pública desfavorável à polícia não se deve apenas ao noticiário sobre a ação de maus policiais, nem só à experiência cotidiana do cidadão em seus contatos com a polícia ou às lembranças do período da ditadura, ou às chacinas da Candelária e de Vigário Geral, no Rio de Janeiro, e do Carandiru, em São Paulo, ou mais recentemente ao desaparecimento do pedreiro Amarildo Dias de Souza, após ser levado para a base de uma Unidade de Polícia Pacificadora. Como detalha Muniz (1999), são muitos os fatores que explicam os maus desempenhos da polícia e a estigmatização do policial. A consequência disso está nos resultados de uma pesquisa, feita em sete estados e no Distrito Federal, que mostra que sete a cada dez brasileiros não confiam nos agentes que, em princípio, estariam a serviço de sua segurança (Anuário Brasileiro de Segurança Pública 2014).

O termo "estigma" foi inicialmente utilizado pelos gregos para se referirem a sinais corporais, como cortes ou queimaduras, que indicavam escravos, criminosos ou 
traidores. Já em termos mais modernos, Goffman (1963) amplia o escopo de exemplos de estigma: deformidades físicas, vícios, doença mental, raça, nação, religião e passagens por presídios ou outro tipo de instituição total, o que inabilita a uma aceitação social plena.

No caso do policial, a marca do estigma é a farda, uma característica distintiva que é imediatamente evidente; é ela que o encaixa na categoria dos desacreditados (GOFFMAN, 1963, p. 14). Como tal, ele deixa de ser considerado uma pessoa comum e total, isto é, que ocupa outros papéis sociais como o de pai ou filho.

Logo, encontros com policiais, especialmente nas comunidades em estudo, são vistos como situações até certo ponto angustiantes. Do lado dos moradores, há desconfiança e a expectativa de maus tratos por parte da polícia. Do lado dos policiais, há insegurança quanto ao modo como vão ser tratados, mas há também a revolta por serem vistos antecipadamente como maus policiais.

Considerando-se que moradores e policiais não podem evitar seus encontros e que, se os policiais são reduzidos a desonestos e truculentos e moradores a traficantes ou pessoas a seu serviço, um trabalho de limpeza moral precisa ser realizado por ambas as partes.

As noções simbólicas de limpeza e sujeira, no âmbito da Antropologia, estão intimamente relacionadas às de ordem e desordem. Indivíduos que ameaçam a ordem realizam, portanto, um trabalho de sujeira moral, o que está sujeito a sanções. Ocorre uma contaminação quando alguém passa da condição simbólica de limpo à de sujo. Nesses casos, de acordo com Douglas (1976, p. 109), determinado sistema de valores e um tradicional arranjo das coisas são violados. No entanto, evitar ter contato com objetos, pessoas ou situações que têm um potencial contaminador nem sempre é possível ou uma questão de escolha, como afirma Menezes (2015, p. 181).

É o caso, por exemplo, de moradores de comunidades cariocas que veem muitas vezes sua imagem associada à dos traficantes (MACHADO DA SILVA, 2008). A contiguidade territorial pode ser suficiente para que quem habita em outras áreas da cidade compreenda que quem vive numa comunidade não está em conformidade com os padrões que sustentariam 
a ordem nesse território. Assim, muitos membros deste grupo desenvolvem um trabalho diuturno de limpeza moral, isto é:

na tentativa de enfrentar os estigmas derivados das imagens de "conivência", os moradores de favelas desenvolvem um permanente esforço para provar ao restante da população da cidade que são pessoas "de bem", honestas, confiáveis, pacíficas e sem participação ativa na "sociabilidade violenta". (MACHADO DA SILVA, 2008, p. 23)

No contexto das comunidades em processo de pacificação, os "jogos de contaminação" se complexificam (MENEZES, 2015), tornando o território uma complexa rede de vigilância. Por um lado, os policiais monitoram as ações dos traficantes, que, por sua vez, vigiam os policiais. Por permanecerem nas comunidades, os policiais vigiam também os moradores, o que obriga estes a lidarem com dois esforços de não contaminação. O primeiro deles diz respeito aos esforços de limpeza moral para não serem confundidos com traficantes, já que são vigiados pela polícia através das câmeras instaladas nesse território e das frequentes abordagens por que passam. O segundo se refere aos esforços de não serem vistos como pessoas a serviço da polícia em decorrência das situações de aproximação, já que são monitorados também pelo tráfico. Por sua vez, os moradores vigiam também os passos da polícia, para denunciar desvios de conduta e desrespeitos aos direitos do cidadão.

Nesse contexto, o espetáculo da prática policial pode servir também à prática da limpeza moral, como no vídeo aqui apresentado em que os policiais estavam cientes de que estavam sendo gravados. Esse trabalho é o nosso objeto de estudo.

\section{Metodologia}

Os dados desta pesquisa consistem na transcrição multimodal de um vídeo postado no Youtube no dia 22 de dezembro de 2013 com o título: "POLICIAL DA UPP AGREDINDO MORADOR". Para fins deste trabalho, estamos chamando de cinegrafista aquele que gravou o vídeo e que interage não só com uma plateia oculta projetada, mas também com os policiais e um participante ausente. Pelas informações apresentadas no transcorrer do vídeo, sabe-se que esse cinegrafista acompanhava o suspeito na hora da abordagem policial. Sabe-se também que o primeiro motivo 
para a condução à delegacia foi o fato de, na hora da abordagem, o acompanhante do cinegrafista ter colocado a mão no bolso, o que poderia ser interpretado como a busca de uma possível arma. É esse cinegrafista que dá o enquadramento da cena como uma denúncia de truculência na ação policial, como mostra o excerto 1 , linha 10 e 11 .

Quanto à postagem do vídeo, não é possível saber se o cinegrafista foi o autor. É muito comum que os conteúdos digitais sejam compartilhados por muitos sem o devido registro do autor/produtor. A pessoa que postou o vídeo se identifica como KatKat e, na imagem do seu perfil, há um rosto feminino pintado com a máscara do filme "V de Vingança", utilizada por muitos manifestantes que foram às ruas nos protestos que ocorreram no Brasil em 2013.

Na descrição do vídeo, encontram-se estas frases: “É assim que atuam os policiais das UPPs. Essa é a da Vila Cruzeiro." Sobre o canal, está escrito: "Canal, SEM FIM LUCRATIVOS, que deseja compartilhar ideias e imagens da mídia alternativa com o objetivo de maior transparência no relato dos fatos. Incluem-se aí documentários, reportagens e tudo mais que possa ser interessante a quem procura o gênero. " O canal de KatKat tem mais de 500 inscritos e mais de 900.000 visualizações. Na página, é possível conferir ainda que o vídeo que selecionamos como objeto para a nossa análise já teve mais de 8.000 visualizações.

Essa gravação, cuja duração é de 3'32", foi transcrita segundo modelo proposto por Jefferson (1984) e, por se tratarem de dados multimodais, inclui descrições relativas à linguagem não-verbal, como gestos, posição do corpo, direção do olhar, dentre outras, e alguns quadros do vídeo que consideramos especialmente relevantes para os fins deste estudo. A proposta de uma análise multimodal das ações sociais está atrelada à ideia de que, no seio das ações humanas, a linguagem verbal se apresenta integrada a um rico sistema ecológico, não figurando, portanto, como um sistema autônomo (GOODWIN, 2010, p. 149).

Ocenário da gravaçãoé uma ladeira. Entre os participantes da interação estão três policiais: Renan, que aparece na tela desde o início do vídeo; Luís, que traz as algemas e também tem suas ações registradas em boa parte do vídeo; e Roberto, que assume o turno poucas vezes e quase não aparece na filmagem, mas está presente desde o início também. Além 
dos policiais, participam da interação situada o rapaz que está sendo conduzido à delegacia (João), o colega que estava junto dele durante a abordagem e que registra a cena (Vitor), uma mulher que passa na hora que está sendo gravado o vídeo (Narareth) e alguém que fala ao telefone com Vitor em determinado momento da gravação.

Na transcrição, foram mantidos aqui os nomes que são pronunciados no vídeo de maneira compreensível (Luís, Rita e Nazareth), afinal o material já é de domínio público. Os outros nomes são fictícios (João, Vitor, Renan e Roberto), uma vez que não se tornam conhecidos durante a cena.

Em termos de procedimentos analíticos, a questão interacional aqui apresentada emergiu dos dados. Logo o primeiro procedimento foi o de selecionar as sequências em que foi observado o trabalho de limpeza moral por parte dos policiais. É sobre essas sequências que dirigimos nosso olhar, analisando-as como co-construções produzidas a partir das ações do cinegrafista e dos policiais.

\section{A negociação dos trabalhos de sujeira/limpeza moral}

O vídeo se inicia no exato momento em que o policial comunica ao suspeito a ordem de condução à delegacia:

\section{Excerto 5}

A imagem a seguir é a que se apresenta no exato segundo em que se inicia o vídeo publicado.

Figura 1 - imagem da linha 1

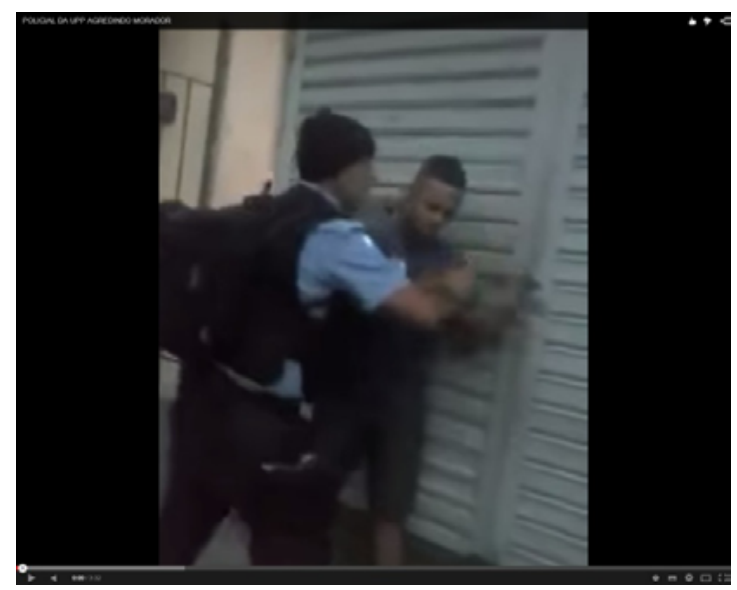




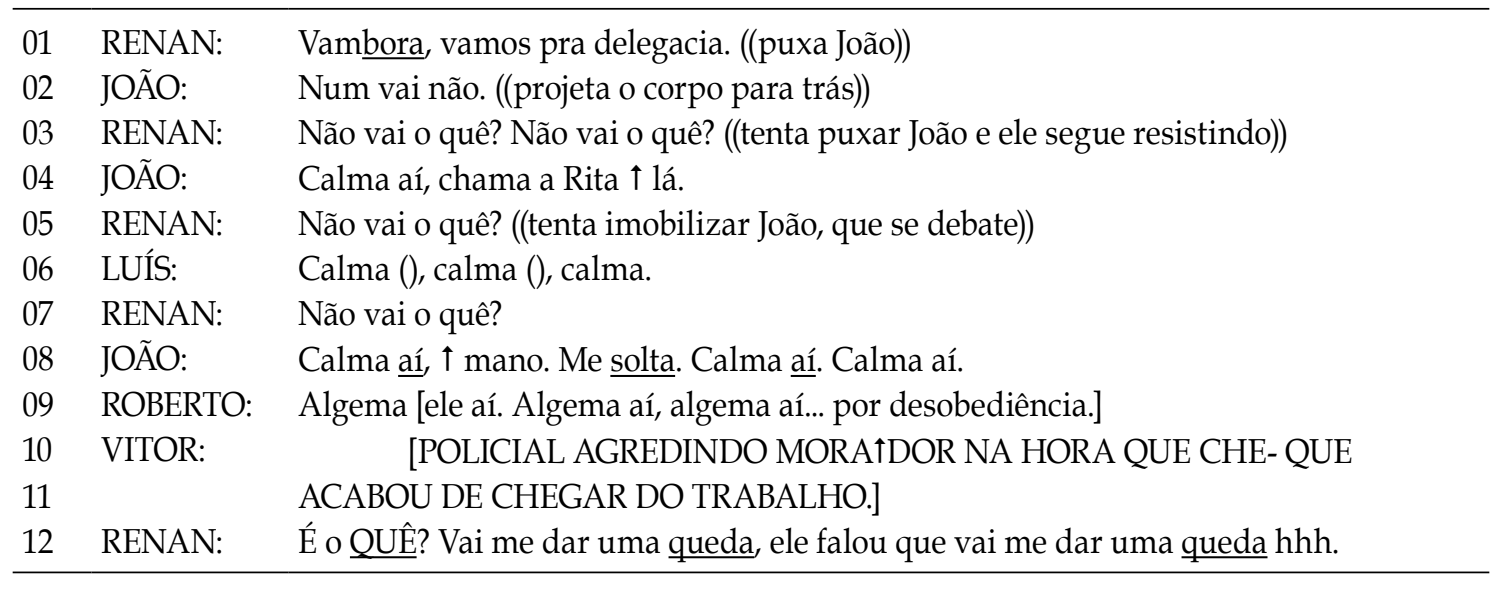

O vídeo se inicia com um trabalho mútuo de ratificação entre Renan e João, os únicos que aparecem na tela nesse momento. Nas linhas 1 e 2, encontramos o par adjacente ordem-recusa. O contato físico dos dois sujeitos que estão em foco ratifica o seu envolvimento nessa interação: enquanto o policial puxa João, o rapaz projeta seu corpo para trás.

A partir dessa sequência, inicia-se uma grande sequência marcada pela resposta do policial à resistência e por um crescente uso da força. $O$ policial passa a responder ao desacato do suspeito com uma pergunta que realiza a ação de lembrar quem manda ali (não vai o quê?). A resposta à não aceitação do desacato e o crescente uso da força levam o suspeito a realizar duas ações: pedir calma ao policial e ajuda a uma pessoa que passava pela cena (Chama a Rita). Com a intensificação do conflito, é a vez de um outro policial entrar em cena para realizar o mesmo pedido (calma). Diante da reiteração de afirmação de autoridade de Renan (Não vai o quêe?), o suspeito realiza dois pedidos (Calma aí, Tmano. Me solta. Calma aí. Calma aí.), embora continue mostrando resistência. Nesse momento, um terceiro policial entra em cena recomendando ao colega o uso de algemas (Algema [ele aí. Algema aí, algema aí) e apresentando uma explicação (por desobediência). A inclusão dessa informação sugere o primeiro trabalho de limpeza moral. Partindo do pressuposto de que os policiais conhecem as normas para o uso de algemas, de modo que não seria necessário que um policial apresentasse essa justificativa a outro, supõe-se que essa informação foi dirigida à audiência para mostrar que estavam agindo de modo adequado. 
É nesse momento que o cinegrafista dirige-se àquele que assistirá ao espetáculo revelando o seu enquadre da cena por meio de uma manchete (POLICIAL AGREDINDO MORA TDOR NA HORA QUE CHE- QUE ACABOU DE CHEGAR AO $T R A B A L H O)$. Esse enquadre ratifica dois atributos do agente policial: i) a truculência; ii) a injustiça, ao categorizar o suspeito como um trabalhador.

Na sequência, a resposta à acusação é feita por Renan, que torce o tronco e o pescoço, voltando sua cabeça para a direção da câmera quando afirma "É o QUÊ? Vai me dar uma queda, ele falou que vai me dar uma queda hhh." (linha 12). Os quadros a seguir registram essa movimentação do policial.

Figura 2 - imagem da linha 11

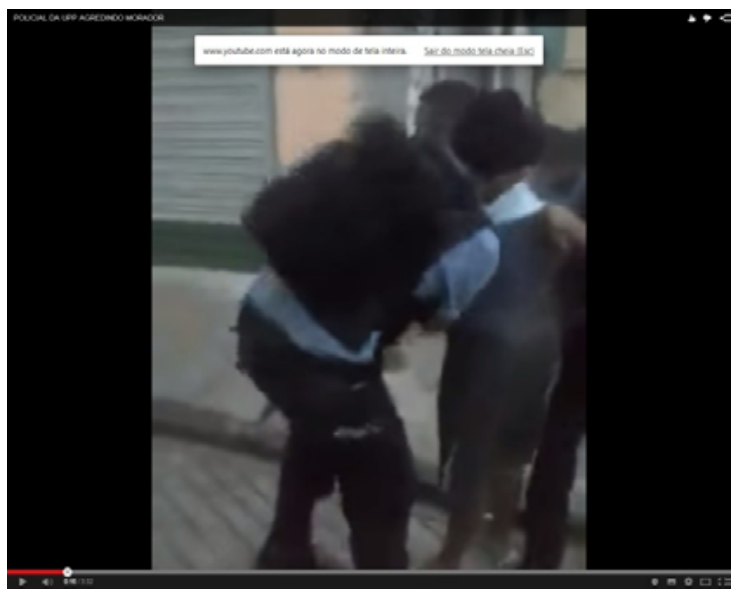

Figura 3 - imagem da linha 12

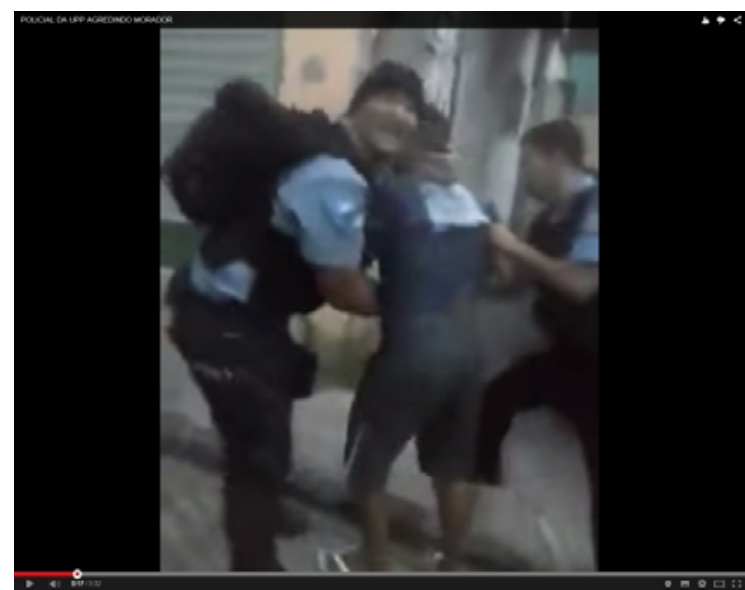

Cabe destacar aqui que a ação de conter o suspeito e algemá-lo se desenrola em um ponto, e o policial Renan volta o seu olhar e a parte de cima do seu corpo para o lado oposto quando chama atenção para o comportamento de João, indicando que não está engajado apenas na ação de conduzir um suspeito à delegacia, mas também está comprometido com a espetacularização da cena, ou seja, com o aproveitamento do espetáculo de sua prática para realizar um trabalho de limpeza moral. Ao comunicar à plateia a ameaça produzida pelo suspeito, Renan relaciona a ação de João não como uma ação típica de um trabalhador, mas sim de um mau elemento, indicando que o uso da força está diretamente relacionado a ações como a de resistência à ordem e ameaça aos policiais. 
No excerto 6, inicia-se a ação de colocação das algemas.

\section{Excerto 6}

\begin{tabular}{|c|c|c|}
\hline $\begin{array}{l}28 \\
29\end{array}$ & JOÃO & $\begin{array}{l}\text { Qual foi? Quer me esculachar, parceiro? Qual †foi, mano? Qual †foi? Nós } \\
\text { estamos aí, mano. Eu tô respeitando. }\end{array}$ \\
\hline 30 & LUÍS: & $\begin{array}{l}\text { Não está respeitando ninguém. Não está respeitando ninguém. } \\
\text { ((puxa o braço de João e começa a algemá-lo)) }\end{array}$ \\
\hline 31 & & \\
\hline 32 & VITOR: & Você achou ele com alguma coisa pra tu está fazendo i- com esses atos assim? \\
\hline 33 & & \\
\hline 34 & RENAN: & ((vira-se para Vitor)) Desobediência, desobediência. \\
\hline 35 & VITOR: & Ele só [tirou o celular do bolso] \\
\hline 36 & RENAN: & {$[<$ resistência>, <resistência>, ] < desobediência>, anota aí. } \\
\hline
\end{tabular}

A fala de João, na linha 28 e 29, realiza uma avaliação da ação dos policiais (Qual foi? Quer me esculachar, parceiro), seguida de uma justificativa para a avaliação negativa (eu tô respeitando), o que é negado por um dos policiais (Não está respeitando ninguém).

Em um trabalho de equipe, o cinegrafista introduz, na linha 32 , uma pergunta dirigida ao policial, mas tendo como alvo a audiência: ("Vocêachou ele com alguma coisa pra tu está fazendo i-com esses atos assim?"). Essa pergunta chama a atenção para a falta de um motivo justo para a detenção. O suspeito não portava droga, arma, nada que o incluísse na categoria bandido. Sem responder diretamente à pergunta de Vitor, Renan repete o motivo da detenção (Desobediência, desobediência). Na mesma direção, Vitor introduz uma informação envolvendo o ato da abordagem, linha 35, que aponta para uma possível má interpretação dos policiais sobre as intenções do suspeito de colocar a mão no bolso. Sem responder diretamente ao questionamento de Vitor, Renan, como quem faz um depoimento numa delegacia de polícia, declara motivos da detenção (resistência e desobediência). Essa informação funciona como trabalho de limpeza moral, na medida em que ela implica a correção do desempenho do policial, a legalidade de suas ações.

Os quadros a seguir apresentam a movimentação da parte superior do corpo de Renan entre as linhas 33 e 34 . Durante as linhas 35 e 36, esse policial permanece com a cabeça entortada para a sua direita de modo a fitar Vitor e a lente da câmera (como se vê no segundo quadro), mesmo que a ação de algemar o suspeito esteja se desenrolando em outra direção. 
Figura 4 - imagem da linha 33

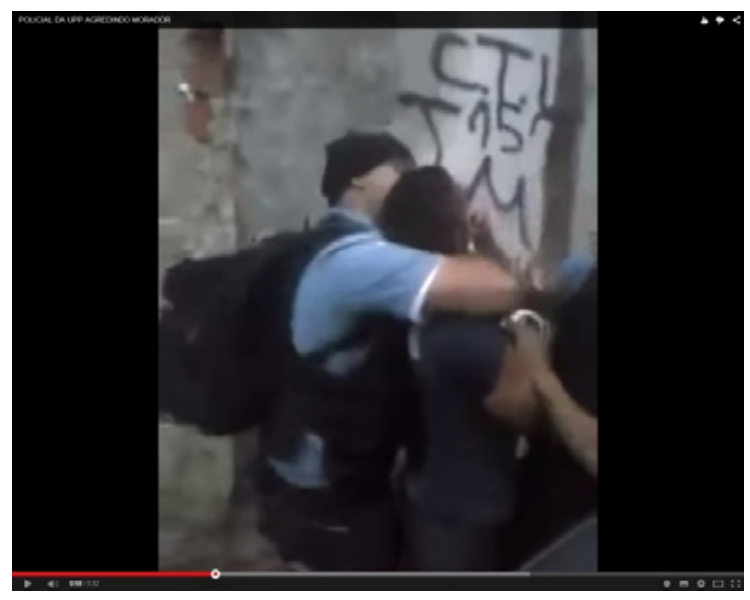

Figura 5 - imagem da linha 34

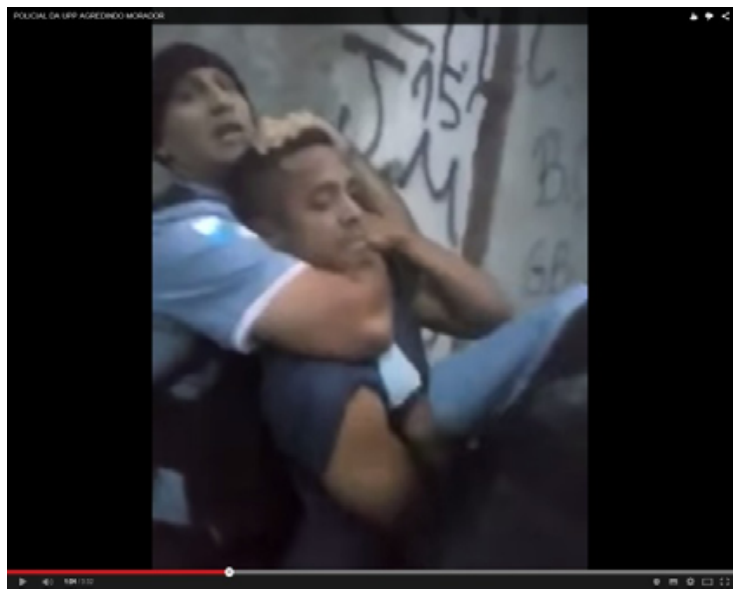

Mais uma vez, nota-se que a ação se desenrola em um ponto, e Renan volta o seu olhar e a parte de cima do seu corpo para outro ponto. Isso evidencia que os policiais lidam com duas tarefas. A central, a de prender, mostra a orientação do policial para um único ouvinte ratificado, o suspeito. A outra tarefa é a de interagir com o alvo, a plateia oculta, para se defender da acusação implícita nas ações realizadas pelo cinegrafista. Observa-se, assim, que policiais e cinegrafistas disputam a produção e edição do espetáculo, no sentido de influenciar a audiência na interpretação da cena.

No excerto 7, a ação de Vítor de insistir na detenção sem motivos justos é atropelada pelo toque de seu celular. A saída de Vitor da interação situada volta a colocar em foco a interação policial-suspeito, como mostram as linhas 76 e 77:

\section{Excerto 7}

71 ROBERTO: Pera aí, vai na moral. Pode ir na moral?

72 VITOR: Vocês acharam ele com alguma coisa?

$73 \quad$ ((um celular toca))

74 VITOR: Os caras estão com João aqui. Está dando a maior merda aqui. Espera aí. To

75 ocupadão.

76 JOÃO: $\quad$ Tu é um frouxo, cara. Vamos ver se tu é sujeito homem. Papo reto. Tu vai

77 tomá-lhe um quedão meu, parceiro.

78 RENAN: ((vira-se para Vitor sorrindo)) Filma aí... hhhh... Isso aí. Filma aí. Filma aí.

79 LUÍs: Isso aí, filma isso aí. 
Mais uma vez, João xinga e ameaça o policial que o está conduzindo à delegacia, ações que de um certo modo ratificam à categoria de suspeito em que foi colocado pelos policiais. Sem responder aos xingamentos e ameaças, Renan, como mostram os quadros que se seguem, continua caminhando com o suspeito, mas entorta a cabeça para a direita para fitar Vitor e a lente da câmera.

Figura 6 - imagem da linha 77

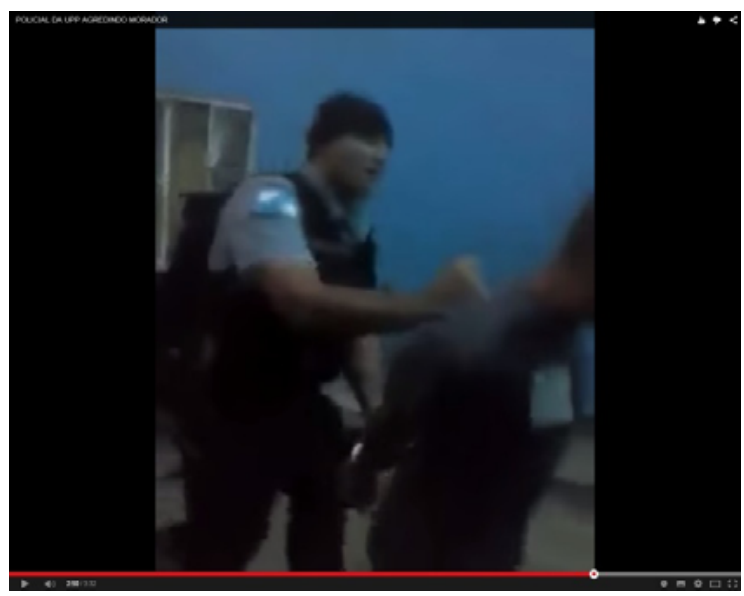

Figura 7 - imagem da linha 78

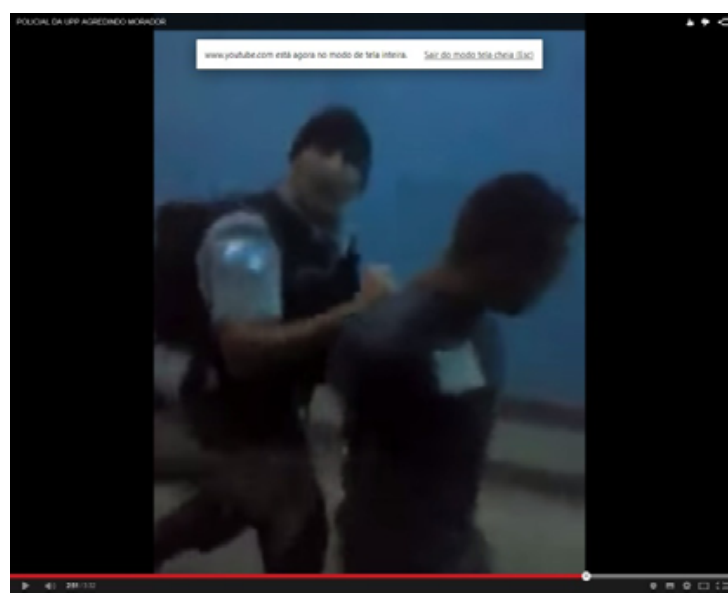

Sorrindo, Renan endereça sua fala a Vitor, pedindo para que filme o comportamento de João, o que é reforçado por outro policial na linha 79. A interação com a plateia torna-se o foco. O comportamento de João é utilizado como uma evidência de que os policias nem sempre agem conforme o estereótipo.

O duelo de projeção de enquadres conflitantes parece atribuir à plateia projetada o papel de júri, isto é, de quem vai decidir qual é a verdade, quem é a vítima, quem está certo ou está errado. Enquanto a câmera, com outras palavras, diz: "olha o que os policiais estão fazendo", os policiais, por sua vez, dizem "olha o que eles estão fazendo". Percebe-se, portanto, que Vitor torna a gravação da cena uma denúncia do abuso do poder policial, enquanto os policiais usam a filmagem para realizar um tipo de trabalho de limpeza moral, como um meio de descontaminação da imagem de mau policial. 


\section{Considerações finais}

O quanto a noção de espetáculo ainda pode nos ajudar a compreender o mundo contemporâneo? Com essa pergunta, nos propusemos a examinar um tipo de espetáculo produzidos por cidadãos com o auxílio das tecnologias oferecidas pelos telefones celulares. Como foco, analisamos um vídeo postado na internet que registra a condução de um suspeito à delegacia.

Algumas diferenças foram observadas com relação às imagens estudadas por Debord. Se a acumulação de imagens midiáticas foi relacionada, por esse pensador francês, às condições de produção capitalista no final dos anos 60 , o registro e a transmissão da imagem, no espetáculo aqui examinado, estão relacionados às condições de vida numa sociedade em que as relações sociais são marcadas pela violência e pela falta de confiança, o que justifica a prática da vigilância.

Outra diferença diz respeito ao poder do produtor das imagens sobre a sua audiência. Para Debord, a mídia é um instrumento de manipulação que adormece consciências (NEGRINI \& AUGUSTI, 2013, p. 7). No caso em estudo, a disputa para coproduzir e coeditar o espetáculo dá à plateia alguma margem para decidir por si própria se há uma versão verdadeira e qual é ela. Mesmo que ocorra manipulação, ela é disputada por quem vigia e por quem é vigiado.

O processo, portanto, de sujeira/limpeza moral é coconstruído na interação. Se quem vigia conduz o olhar da plateia para a ação violenta injusta do policial, quem é vigiado usa os mesmos canais para realizar um trabalho de limpeza moral, de descontaminação de uma farda que veste também maus policiais.

Em resumo, a espetacularização da cena policial tem impactos na própria prática policial. Como mostrado em nossa análise, a superposição de uma cena física situada e uma cena projetada para uma audiência oculta leva os policiais a realizarem um duplo trabalho. Por um lado, estão orientados para as suas tarefas como policial, por outro lado, se orientam para uma performance que coloque em questão os estigmas que lhes são atribuídos. 


\section{REFERÊNCIAS}

Anuário Brasileiro de Segurança Pública 2014. Fórum Brasileiro

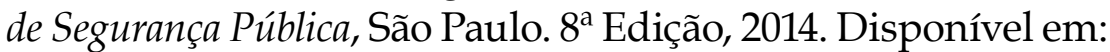
$<$ http://www.forumseguranca.org.br/storage/download// anuario_2013-corrigido.pdf>. Acesso em: 30/11/2015.

ANTAKI, Charles. Applied Conversation Analysis. Basingstoke: Palgrave-Macmillan, 2011.

AUGUSTI, A.; NEGRINI, M. O legado de Guy Debord: reflexões sobre o espetáculo a partir de sua obra. Biblioteca On-line de Ciências da Comunicação. Disponível em: < http://www.bocc. ubi.pt/pag/negrini-augusti-2013-legado-guy-debord.pdf $>$. Acesso em: 30/11/2015.

BRUNO, F. Mapas de crime: vigilância distribuída e participação na cibercultura. E-compós, Brasília, v. 12, n. 2, maio/ago. 2009.

DEBORD, Guy. A Sociedade do Espetáculo. Rio de Janeiro: Contraponto, 1997[1967].

DOUGLAS, Mary. Pureza e Perigo. São Paulo: Editora Perspectiva, 1976.

ESCHHOLZ, S.; SIMS BLACKWELL, B.; GERTZ, M.; CHIRICOS, T. Race and attitudes toward the police, assessing the effects of watching "reality" police programs. Journal of Criminal Justice, 30, p. 327-341, 2002.

GOODWIN, C. Multimodality in human interaction. Calidoscópio, Vol. 8, n. 2, p. 85-98, 2010.

GOFFMAN, E. A situação negligenciada. In: RIBEIRO, B. T; GARCEZ P. M. (Orgs.). Sociolinguistica Interacional. Porto Alegre: Age, 2002 [1964].

Interaction ritual: essays on face-to-face behavior. New York: Doubleday Anchor, 1967.

. Estigma: notas sobre a manipulação da identidade deteriorada. Rio de Janeiro: Zahar Editores, 1978.

Encounters: Two Studies in the Sociology of Interaction. Indianapolis: Bobbs-Merrill, 1961. 
. Behavior in Public Places: Notes on the Social Organization of Gatherings. New York, 1963.

HUTCHBY, Ian. Conversation and Technology: from the Telephone to the Internet. Cambridge: Polity Press, 2001.

KATRIEL, T. Rethinking the Terms of Social Interaction. Research on Language and Social Interaction, 32 (1\&2), 85-101, 1999.

MACHADO DA SILVA, Luiz Antonio. Vida sob cerco: violência e rotina em favelas do Rio de Janeiro. Rio de Janeiro: Nova Fronteira, 2008.

MENEZES, P. Entre o "fogo cruzado" e o "campo minado": uma etnografia do processo de "pacificação" de favelas cariocas. 2015. 414f. 2015. Tese (Doutorado em Sociologia) - Instituto de Estudos Sociais e Políticos, Universidade do Estado do Rio de Janeiro, Rio de Janeiro, 2015.

OLIVEIRA, M.C.L.;PEREIRA, M.G. D. A interação tecnologizada em relações de serviço: um estudo das possibilidades e restrições da tecnologia. Calidoscópio. V.3, n. 2, maio/agosto de 2005. p. $118-130$

PINTO, J. M. F. “Espaços Efémeros - Possibilidades virais n' A Sociedade do Espetáculo". Revista de Comunicação e Linguagens, Universidade Nova de Lisboa, RCL 34: 143-156, 2005.

PORTELA JÚNIOR, A. Para compreender a sociedade do espetáculo: revisitando o pensamento de Guy Debord. Revista Anagrama. São Paulo, v.2, n.3, p.01-07, mar./maio 2009.

PROSISE, T.; JOHNSON, A. Law enforcement and crime on Cops and World's Wildest Police Videos: anecdotal form and the justification for racial profiling. Western Journal of Communication, 68, p. 69-85, 2004.

SARANGI, S. The conditions and consequences of professional discourse studies. In R. Kiely, P. Rea-Dickins, H. Woodfield and G. Clibbon eds., Language, Culture and Identity in Applied Linguistics. London: Equinox, 2006. p. 199-220. 


\section{Abstract \\ Smile: you are on camera. Spectacularization of police practice and moral cleaning work.}

The imaging technologies offered by cell phones allow any common citizen to produce their own spectacles and make them public. In this paper, we focus on one of the daily events that have been widely reported in Brazil: the actions of police officers that experience a new form of policing called "Pacifying Police Unit" ("Unidade de Policia Pacificadora", UPP) in favelas in the city of Rio de Janeiro. Using the theoretical apparatus of Applied Conversation Analysis (ANTAKI, 2011) and studies of multimodality (GOODWIN, 2000; 2010), we conducted a multimodal analysis of a video, posted on YouTube, which records the moment when police officers face resistance of a suspect who refuses to be driven to the police station. Considering that police officers are aware that their actions are being recorded and their image of police officers are in general under constant suspicion (MUNIZ, 1998), our goal is to investigate the types of "moral cleaning" mechanisms (MACHADO DA SILVA, 2008) used by them to escape from a stigma. Based on the analysis of this case, we claim that the technological mediation makes communication seem less unilateral, through mechanisms such as the inclusion of information not captured by the cameraman and explanation of the rules that guide police officers' actions, especially with regard to the degree of force. Making "moral cleaning" efforts, police officers try to build the image of professionals who act according to the precepts of military-police ethics, as the performance of their duties with fairness and justice.

Keywords: spectacularization; policing; "Pacifying Police Unit"; "moral cleaning"; technological mediation. 